\title{
Speciation of Molybdates under Hydrothermal Conditions
}

\author{
Johannes Noack, ${ }^{\text {a,b }}$ Frank Rosowski, ${ }^{\text {b,c }}$ Robert Schlögl, ${ }^{\text {a }}$ and Annette Trunschke ${ }^{\text {aa }}$
}

Dedicated to Prof. Martin Jansen on the Occasion of his 70th birthday

Keywords: Raman; in situ; molybdates; MoV oxides

\begin{abstract}
In situ Raman spectroscopy was applied to investigate the speciation of molybdates under hydrothermal conditions in $0.2 \mathrm{M}$ aqueous solution in the temperature range between $20^{\circ} \mathrm{C}$ and $200^{\circ} \mathrm{C}$ and at $\mathrm{pH}$ values between 7 and 1 . The nature and abundance of molecular and supra-molecular species differs significantly compared to the distribution of species under ambient conditions at the same $\mathrm{pH}$. Whereas heptamolybdate $\mathrm{Mo}_{7} \mathrm{O}_{24}{ }^{6-}$ dominates under ambient pressure at $25^{\circ} \mathrm{C}$ in the $\mathrm{pH}$ range between 6 and 5 , at 170 $190^{\circ} \mathrm{C}$, chain-like or molecular structures of dimolybdates $\mathrm{Mo}_{2} \mathrm{O}_{7}{ }^{2-}$ and trimolybdates $\mathrm{Mo}_{3} \mathrm{O}_{10}{ }^{2-}$ are preferentially formed.
\end{abstract}

In acidic solutions $(\mathrm{pH}<2)$, supramolecular species, like $\mathrm{Mo}_{36} \mathrm{O}_{112}{ }^{8-}$, which generally predominate at $25^{\circ} \mathrm{C}$, do not occur at $\mathrm{T}>100^{\circ} \mathrm{C}$. Instead, $\beta-\mathrm{Mo}_{8} \mathrm{O}_{26}{ }^{4-}$ is the final molecular precursor of precipitation reactions that was detectable by Raman spectroscopy. The structural type of the solid phase formed through addition of vanadyl sulfate under hydrothermal conditions is sensitively controlled by the nature of the molecular precursor, which is adjusted by the $\mathrm{pH}$. In acidic medium, hex. $\mathrm{MoO}_{3}$ (ICSD 80290) is formed, while at $\mathrm{pH}=5.8$ nano-crystalline M1 (ICSD 55096) was obtained.

\section{Introduction}

Hydrothermal synthesis gives access to various material families including oxides, carbides, nitrides, openframework and hybrid structures, metallics and intermetallics, and carbons. Proper choice of reaction conditions, and the addition of complex-forming, capping or structure-directing agents lead to solid particles characterized by different morphology and render the controlled synthesis of hierarchical pore structures possible. Hydrothermal routes benefit from kinetic control that facilitates the formation of metastable phases, which often comprise the desired functionality. ${ }^{[1]}$ This benefit is accompanied by the disadvantage that predictions of product properties are oftentimes quite difficult. Spectroscopic and analytical studies of inorganic syntheses are particularly important to understand the mechanisms behind the complex reactions under hydrothermal conditions and to rationally

[a] Dr. J. Noack, Prof. Dr .R. Schlögl, Dr. A. Trunschke Fritz-Haber-Institut der Max-Planck-Gesellschaft, Faradayweg 4-6, 14195 Berlin, Germany Fax: (+49) 3084134405 E-mail: trunschke@fhi-berlin.mpg.de

[b] Dr. J. Noack, Dr. F. Rosowski BasCat - UniCat BASF JointLab Technische Universität Berlin, Sekr. EW K-01 Hardenbergstraße 36, 10623 Berlin, Germany

[c] Dr. F. Rosowski BASF SE, Process Research and Chemical Engineering Heterogeneous Catalysis, Carl-Bosch-Straße 38, 67056 Ludwigshafen, Germany

Supporting information for this article is available on the WWW under http://www.chemeurj.org/ or from the author. design experiments for the synthesis of new phases exhibiting designated properties. ${ }^{[\mathrm{d}, 2]}$ We have developed an analytical autoclave (Figure 1) that enables the synthesis of comparatively large batches of oxides according to a new concept that implies a guided synthesis based on spectroscopic information obtained online during the entire experiment. $^{[3]}$ The synthesis is performed automated according to a pre-assigned sequence of reaction steps and the reaction parameters, such as temperature, pressure, power intake of the stirrer, and $\mathrm{pH}$ are measured and recorded.

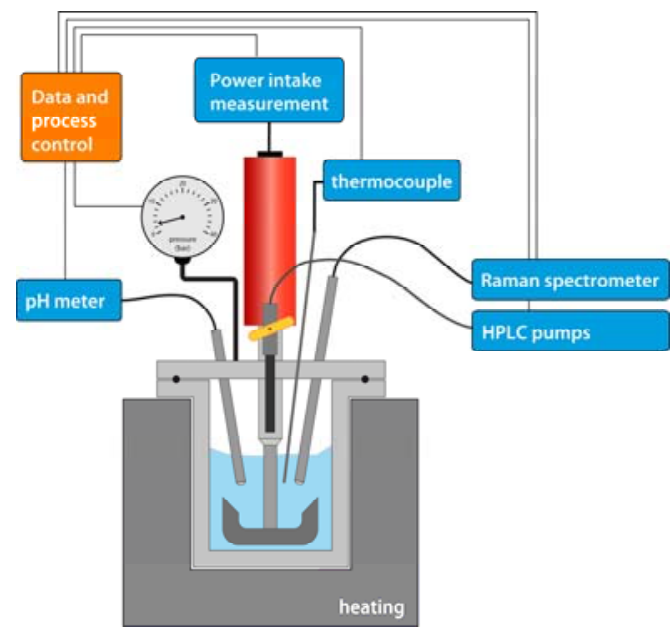

Figure 1. Analytical autoclave used for the in situ investigation of the molybdate chemistry under hydrothermal conditions at various $\mathrm{pH}$. Technical details are described in the experimental section.

The analytical autoclave set-up allows for the in situ investigation of species appearing during the reaction, e.g. polyoxometalates, by Raman spectroscopy and enables the 
directed synthesis to desired phases by adjusting the reaction parameters accordingly, e.g. through addition of reactants or changing the $\mathrm{pH}$ by using the HPLC pumps. Other analytical tools, such as IR and UV-vis spectroscopy or other scattering techniques to investigate the chemical changes and dissolution or phase formation behavior under hydrothermal conditions can also be applied in that set-up.

The nature of metal oxide clusters is not only of importance for understanding the mechanisms of phase formation in the synthesis of metal oxides but also in the contrary process, meaning the dissolution of minerals that occur under extreme conditions in our earth's crust. Molybdate species have been investigated by XANES in aqueous solutions in presence of chloride, iron and manganese ions. ${ }^{[4]}$ Also the dipole properties of water are significantly changed under high temperatures and pressures, which has an impact on the dissolution behavior of minerals. ${ }^{[5]}$

Polyoxometalates with different compositions and structures have been investigated for decades by now with the prospects of various applications and have been subject of several review articles. ${ }^{[6]}$ Giving a broad overview on the coordination chemistry of the different transition metals, their existence under the reaction conditions applied in the synthesis of metal oxide catalysts has to be further investigated. Previously, we reported the directed synthesis of complex Mo-based mixed oxides through subsequent addition of the required structural building units. ${ }^{[3]}$ With the aim to systematically broaden our knowledge concerning intermediates present under hydrothermal conditions during the synthesis of transition metal oxides, the current study is devoted to the speciation of isopolymolybdates at elevated temperature and pressure and their impact on solid formation upon the addition of vanadium as a second transition metal ion. The objective is to study the speciation of polyoxometalates under conditions that are close to the hydrothermal synthesis of molybdenum oxides and mixed MoV oxides, meaning that the experiments were performed in pure water in the absence of buffer solutions or alkali salts. The physical and chemical properties of water change significantly under hydrothermal conditions with increasing temperature and pressure, in particular the negative logarithm of the ionic product of water $K_{\mathrm{w}}$ decreases from 14 to 11.3 under autogenous pressure from $25^{\circ} \mathrm{C}$ to $200^{\circ} \mathrm{C} .^{[7]}$ For this reason, the ionic strength is not constant during the in situ spectroscopic experiments at variable temperature. The influence of proton concentration and temperature under the conditions of hydrothermal synthesis of MoVbased oxides will be discussed.

\section{Results and Discussion}

The structure of molybdates in aqueous solution is manifold and strongly depends on parameters such as concentration, ionic strength, $\mathrm{pH}$, counter ion, solvent and temperature. The reversible transformation of isopolymolybdates in aqueous solution occurs through hydrolysis and condensation in consequence of changing $\mathrm{pH}$, that is, in contrast to tungstates, a spontaneous process. ${ }^{[8]}$ The degree of polymerization of the individual species can be expressed by calculation of the $\mathrm{Z}^{+}$-value, which is described by the ratio of protons consumed per molybdenum atom in the condensation reaction (Equation 1, in which $v$ corresponds to the stoichiometric coefficient). The $\mathrm{Z}$-value of the solution, taking into account the initial $\mathrm{H}^{+}$ concentration $\left(C_{H^{+}}\right)$, the equilibrium concentration of protons $\left(c_{H^{+}}\right)$and the autodissociation of water under the given reaction conditons (Equation 2), indicates the species to be expected at certain $\mathrm{pH} .^{[9]}$

$$
\begin{aligned}
& Z^{+}=\left|v_{H^{+}}\right| /\left|v_{M_{0} O_{4}^{2-}}\right| \\
& Z=\left(C_{H^{+}}-c_{H^{+}}+K_{w} / c_{H^{+}}\right) / c_{M_{o O}^{2-}}
\end{aligned}
$$

In solution, mostly a mixture of different species exists at the same time. The speciation of molybdates and the effect of concentration and $\mathrm{pH}$ value on the transformation at normal pressure have been investigated thoroughly by potentiometric measurements, ${ }^{[10]} \mathrm{UV} / \mathrm{vis}$ spectroscopy, ${ }^{[1]}$ electrospray mass spectrometry, ${ }^{[12]}$ and Raman spectroscopy. ${ }^{[10 a, 13]}$ In Figure 2, the Raman spectra in the range of the characteristic $\mathrm{Mo}=\mathrm{O}$ vibrations of $0.2 \mathrm{M}$ molybdate solutions at different $\mathrm{pH}$ values from 7.0 to 1.0 are compared for experiments conducted at $25^{\circ} \mathrm{C}$ and ambient pressure (Figure 2a), and at $175^{\circ} \mathrm{C}$ and autogenous pressure of $891 \mathrm{kPa}$ (Figure 2b). The entire range of the spectra from 200 to $1200 \mathrm{~cm}^{-1}$ is shown in the Supporting Information (Figures S1-S2). The comparison of those two experiments reveals significant differences in the distribution of molybdate species at identical $\mathrm{pH}$ values but different temperatures and pressures. Please note, that the bands for the individual species observe a slight shift towards lower wavenumbers due to thermal effects. The center of the band at $749 \mathrm{~cm}^{-1}$ from the sapphire window of the probe, which is used as reference, exhibits a temperature shift of $\sim 4 \mathrm{~cm}^{-1}$ (Figure S3, Supporting Information) in the temperature range between 20 and $190^{\circ} \mathrm{C}$, which is also expected for the molybdate species.

In the experiment performed at $25^{\circ} \mathrm{C}$, the starting $\mathrm{pH}$ of the molybdate solution was adjusted to 9.0 by addition of ammonium hydroxide solution resulting in the preferential occurrence of tetrahedrally coordinated $\mathrm{MoO}_{4}{ }^{2-}$ anions characterized by Mo-O stretching vibrations at 896 and $839 \mathrm{~cm}^{-1}$ and a band at $316 \mathrm{~cm}^{-1}$ (Figure S1, Supporting Information). At $\mathrm{pH}$ values above 7 and $\mathrm{T}=25^{\circ} \mathrm{C}$, the tetrahedral $\mathrm{MoO}_{4}{ }^{2-}$ is the only stable form, which is sequentially polymerized upon acidification (Figure 2a). The condensation reaction is thermodynamically driven by the formation of Mo-O-Mo bonds and the release of $\mathrm{H}_{2} \mathrm{O}$. Accordingly, the resulting structures should be composed of edge-sharing octahedra with a minimum of terminal oxygen atoms. ${ }^{[10 \mathrm{f}]}$ At room temperature, the first step is the direct transformation of monomeric $\mathrm{MoO}_{4}{ }^{2-}$ to heptamolybdate $\left(\mathrm{Z}^{+}=1.14\right)$ that can be followed with Raman spectroscopy by the continuous decrease of the $\mathrm{MoO}_{4}{ }^{2-}$ band at $896 \mathrm{~cm}^{-1}$ and parallel appearance of a band due to the formation of $\mathrm{Mo}_{7} \mathrm{O}_{24}{ }^{6-}$ at $939 \mathrm{~cm}^{-1}$ (Figure 2a). ${ }^{[10 \mathrm{a},}$ 13g, 14] Although, according to Equation 3, a number of 7 molybdate ions and 8 protons are required in total, no indications for stable intermediates with less complexity have been found by Raman spectroscopy and reported so far. The $\mathrm{pH}$ range dominated by heptamolybdate is between 6 and 5 in which $\mathrm{Mo}_{7} \mathrm{O}_{24}{ }^{6-}$ always coexists with other species, such as remaining $\mathrm{MoO}_{4}{ }^{2-}, \mathrm{Mo}_{3} \mathrm{O}_{10}{ }^{2-}$, and its protonated form $\mathrm{HMo}_{7} \mathrm{O}_{24}{ }^{5-[14]}$

$$
7 \mathrm{MoO}_{4}^{2-}+8 \mathrm{H}^{+} \rightarrow \mathrm{Mo}_{7} \mathrm{O}_{24}^{6-}+4 \mathrm{H}_{2} \mathrm{O}
$$


Upon continuing addition of acid, the Raman band maximum of the heptamolybdate shifts to $948 \mathrm{~cm}^{-1}$ at $\mathrm{pH}=4.0$ due to formation of trimolybdate $\left(\mathrm{Z}^{+}=1.33\right)$ with the most intense $\mathrm{Mo}=\mathrm{O}$ band at $950 \mathrm{~cm}^{-1}$ as also found by Himeno et al., ${ }^{[13 \mathrm{a}]}$ or protonation of heptamolybdate, ${ }^{[14]}$ and finally decreases in intensity. Subsequently, new bands at 958 and $969 \mathrm{~cm}^{-1}$ arise, indicating the formation of $\alpha$ - and $\beta$ $\mathrm{Mo}_{8} \mathrm{O}_{26}{ }^{4-} \quad\left(\mathrm{Z}^{+}=1.5\right), \quad$ respectively. Formally, the octamolybdate can be obtained by the addition of $\mathrm{MoO}_{4}{ }^{2-}$ to heptamolybdate consuming four additional protons according to Equation 4.

$$
\mathrm{Mo}_{7} \mathrm{O}_{24}{ }^{6-}+\mathrm{MoO}_{4}^{2-}+4 \mathrm{H}^{+} \rightarrow \mathrm{Mo}_{8} \mathrm{O}_{26}^{4-}+2 \mathrm{H}_{2} \mathrm{O}
$$

The $\alpha$-form is constituted by six edge-sharing $\mathrm{MO}_{6}$-units forming a six-membered ring with each side of the plane being capped by two $\mathrm{MO}_{4}$-tetrahedra. A more dense structure, comprising only edge-sharing $\mathrm{MoO}_{6}$-octehedra is then formed in the $\beta$-octamolybdate by reconstruction. The $\gamma-\mathrm{Mo}_{8} \mathrm{O}_{26}{ }^{4-}$ has been reported as intermediate species in the transformation from the $\alpha$ - to the $\beta$-form, ${ }^{[15]}$ but has not been found in noticeable concentrations as for its thermodynamic and kinetic instability. ${ }^{[13 \mathrm{a}]}$

a)

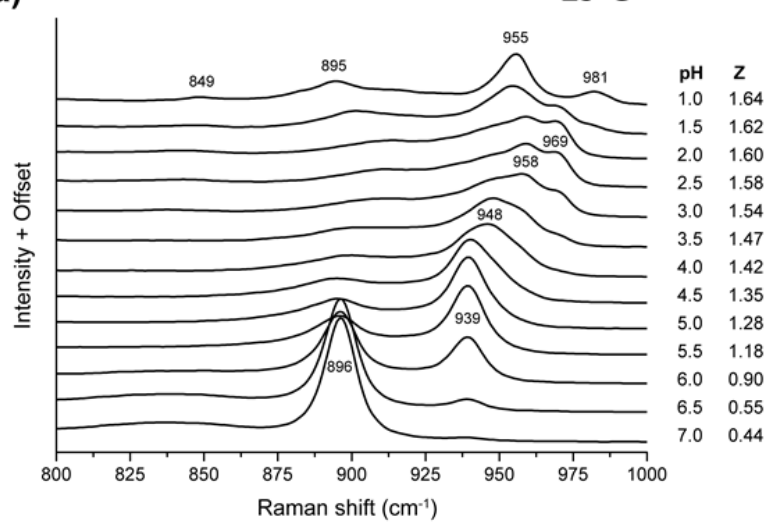

ammonium heptamolybdate solution with $\mathrm{Z}=1.14$ (Figure 3 ) at autogenous $\mathrm{pH}$ values and the thermal decomposition of $\mathrm{Mo}_{36}$ ions in aqueous solution (Figure 4) which serve as reference experiments.

During heating of an aqueous solution of ammonium heptamolybdate from $20^{\circ} \mathrm{C}$ to $190^{\circ} \mathrm{C}$ the speciation is found to change significantly, which is reflected in the variation of the $\mathrm{Mo}=\mathrm{O}$ Raman vibrations (Figure 3a). The relative amount of each species, under the reasonable assumption of identical scattering cross-sections of all the species involved, ${ }^{[13 \mathrm{a}]}$ are visualized in Figure $3 \mathrm{~b}$. The spectra have been simulated using Gaussian functions after subtraction of the background and correction for thermal shift of the respective bands. The species considered in the spectral deconvolution have been restricted to the species expected in the Z-range of the solution and taking into account the different bands in that spectral range with fixed relative intensities (Table S1, Supporting Information).

As the $\mathrm{pH}$ value changes only slightly between 5.4 and 6 , these effects can be attributed to changing equilibria of the different stable species under the given temperature. This is b)

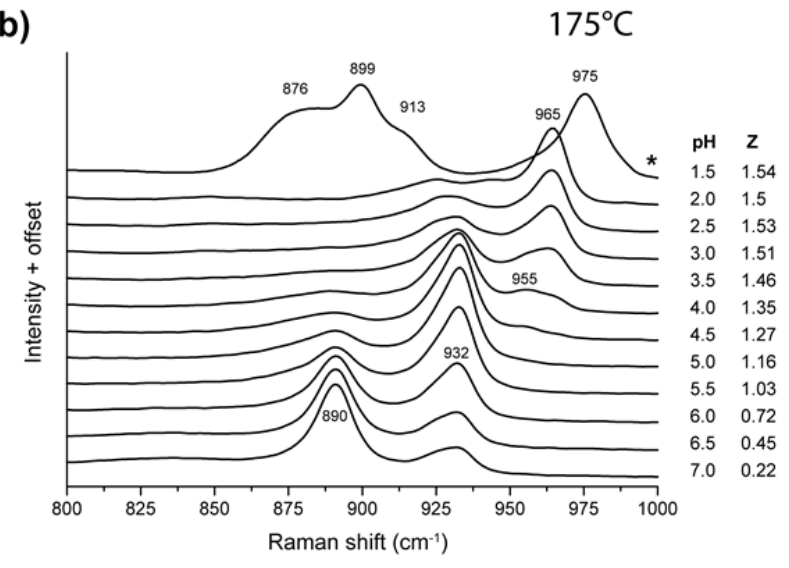

Figure 2. Raman spectra of molybdate solutions (starting concentration $0.25 \mathrm{M}$, final concentration $0.2 \mathrm{M}$ ) at different $\mathrm{pH}$ values from $\mathrm{pH} 7.0$ to 1.0 for $25^{\circ} \mathrm{C}$ (a) and $\mathrm{pH} 7.0$ to 1.5 for $175^{\circ} \mathrm{C}$ (b) with the corresponding Z-values of the solutions; the spectrum marked with * has been scaled by the factor of 0.5 .

In the more acidic regime with Z-values above 1.64, formation of the even more complex isopolymolybdate ion $\mathrm{Mo}_{36} \mathrm{O}_{112}{ }^{8-}\left(\mathrm{Z}^{+}=1.78\right)$ can be observed at $25^{\circ} \mathrm{C}$ evident by the appearance of bands at $981,955,895$, and $849 \mathrm{~cm}^{-1}$, ${ }^{[13 \mathrm{~d}]}$ which is the only stable phase at $\mathrm{pH}$ below 1.0. This $\mathrm{Mo}_{36}$ ion can be described as a centrosymmetric dimer of $\mathrm{Mo}_{18}$ subunits in which two of the Mo atoms become sevencoordinate and form a pentagonal bi-pyramidal unit surrounded by edge-sharing $\mathrm{MO}_{6}$-octahedra. This motif is also found in other highly condensed solid phases, such as the so called $\mathrm{Mo}_{5} \mathrm{O}_{14}$-type, ${ }^{[16]}$ and $\mathrm{M} 1$ phases. ${ }^{[17]}$ Finally, molybdic acid is precipitated from that solution as a white solid at a $\mathrm{pH}$ below 1 . Bands reported for $\mathrm{H}_{2} \mathrm{MoO}_{4}$ in solution $^{[18]}$ at $919 \mathrm{~cm}^{-1}$ are not detected under the present experimental conditions because of the very fast condensation reactions to polymolybdates. The observations made in the experiment at $25^{\circ} \mathrm{C}$ (Figure 2a) are consistent with the literature ${ }^{[10 a, 13 a, 13 d, 13 e]}$ and provide the basis for further variation of the experimental parameters. To understand the differences observed when the same experiment was performed at $175^{\circ} \mathrm{C}$ (Figure $2 \mathrm{~b}$ ), we first discuss the speciation during heating of a $0.2 \mathrm{M}$ aqueous also underlined by the fact, that the reaction is fully reversible; no chemical changes can be observed afterwards. The auto-dissociation of water at elevated temperatures as well as the $\mathrm{pH}$ changes have no significant influence on the $\mathrm{Z}$-value of the investigated molybdate solution and cannot be attributed to the observed changes (Table S2, Supporting Information). A $0.2 \mathrm{M}$ solution of $\left(\mathrm{NH}_{4}\right)_{6} \mathrm{Mo}_{7} \mathrm{O}_{24}$ has a $\mathrm{pH}$ value of 5.4 at $20^{\circ} \mathrm{C}$, and exhibits a mixture of $\mathrm{MoO}_{4}{ }^{2-}$ and $\mathrm{Mo}_{7} \mathrm{O}_{24}{ }^{6-}$ as derived from the bands at 895 and $939 \mathrm{~cm}^{-1}$, while the heptamolybdate species predominates in agreement with the previous experiment (Figure 2a). The slight anisotropy of the band at $939 \mathrm{~cm}^{-1}$ to higher wavenumbers and the difference in the sum of $\mathrm{Z}^{+}$-values of $\mathrm{MoO}_{4}{ }^{2-}$ and $\mathrm{Mo}_{7} \mathrm{O}_{24}{ }^{6-}$ to the initial 1.14 gives reason for the presence of trimolybdate under these conditions, which is also found by Himeno et al. as a minor species under similar conditions. ${ }^{[13 a]}$

When heating that solution under autogenous pressure, the band of the orthomolybdate at $896 \mathrm{~cm}^{-1}$ gradually decreases and the band due to heptamolybdate originally at $939 \mathrm{~cm}^{-1}$ apparently shifts towards higher wavenumbers as a result of strong overlap with the increasing band of trimolybdate at 
$950 \mathrm{~cm}^{-1}$. That is also accompanied by the increase in the $\mathrm{pH}$ value from 5.4 to 5.7 indicating changes in the nuclearity of the molybdates. The spectral deconvolution (Figure $3 b$ ) shows, that both are transformed to other species and completely disappear at $130^{\circ} \mathrm{C}$. At the same time, another band around $956 \mathrm{~cm}^{-1}$ arises together with a peak at $965 \mathrm{~cm}^{-1}$, which is first seen as a shoulder of the main feature and becomes more dominant at higher temperatures. The latter two bands can be attributed to $\alpha$ - and $\beta-\mathrm{Mo}_{8} \mathrm{O}_{26}{ }^{4-}$, respectively which are both not observed under ambient conditions at $\mathrm{pH}$ values above 4.0 in considerable amounts. At $25^{\circ} \mathrm{C}$, octamolybdate occurs in the $\mathrm{pH}$ range between 3.5 and 1.5 (Figure 2a). The band intensity of the $\alpha$ modification shows a maximum around $130^{\circ} \mathrm{C}$ and decreases thereafter for the benefit of the formation of $\beta-\mathrm{Mo}_{8} \mathrm{O}_{26}{ }^{4-}$ which proves to be more stable at elevated temperatures under autogenous pressure. The $\mathrm{pH}$ reaches a maximum at $\mathrm{T}=130^{\circ} \mathrm{C}$ in agreement with progressive condensation, but decreases slightly at higher temperatures suggesting depolymerisation. This is also reflected by the development of a new band at $932 \mathrm{~cm}^{-1}$ that appears for the first time as a shoulder in the spectrum at $80^{\circ} \mathrm{C}$ when heptamolybdate is already substantially decomposed and continuously gains in intensity, finally dominating the spectrum at $190^{\circ} \mathrm{C}$. Since the Z-value of the solution marginally changes during the heating experiment, the formation of octamolybdate ions must go in line with

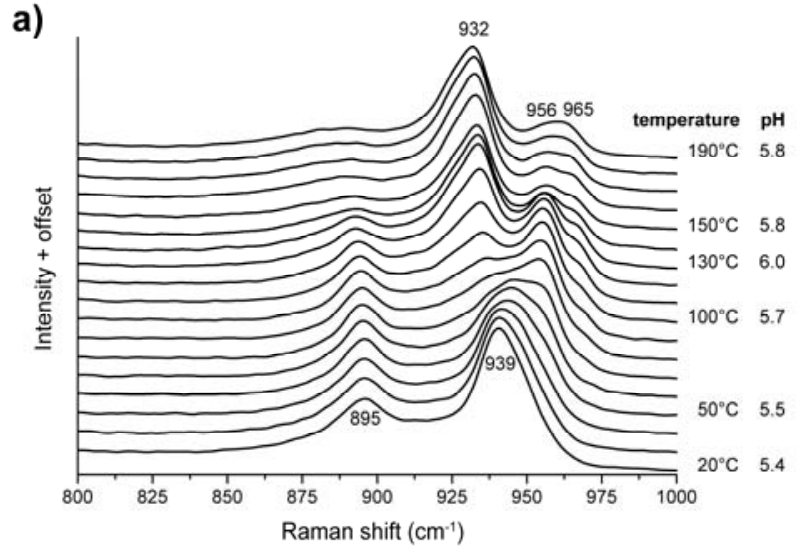

In summary, a $0.2 \mathrm{M}$ aqueous solution of molybdates under autogenous pressure at temperatures between 170 and $190^{\circ} \mathrm{C}$ contains mainly dimolybdate species together with tri-, tetra-, and octamolybdates.

Figure 4 illustrates the thermal stability of $\mathrm{Mo}_{36} \mathrm{O}_{112}{ }^{8-}$ ions in a $0.2 \mathrm{M}$ solution obtained by adjusting an aqueous molybdate solution to a $\mathrm{pH}$ value of 1.5 . The spectrum of the initial $\mathrm{Mo}_{36} \mathrm{O}_{112}{ }^{8-}$ solution exclusively exhibits the characteristic bands of the supramolecular species at 981, 955,895 and $849 \mathrm{~cm}^{-1}$. During heating of that solution the band structure is changed, explicitly from about $50^{\circ} \mathrm{C}$ on an additional band at $969 \mathrm{~cm}^{-1}$ appears and slowly shifts towards higher wavenumbers while the other bands weaken and finally disappear at $70^{\circ} \mathrm{C}$. The formation of the hexagonal- $\mathrm{MoO}_{3}$ phase (ICSD 80290) ${ }^{[21]}$ is well observed by the very intense bands at 973 and $901 \mathrm{~cm}^{-1}$ with shoulders at 878 and $911 \mathrm{~cm}^{-1}$. Obviously, the $\mathrm{Mo}_{36} \mathrm{O}_{112}{ }^{8-}$ ion is decomposed at quite low temperature to form the bulk hex. $-\mathrm{MoO}_{3}$ phase. This also goes in line with the loss of structural features, such as the pentagonal bipyramidic units of the $\mathrm{Mo}_{36}$-unit and formation of a loose network of edgeand corner sharing $\mathrm{MO}_{6}$-units with large pores. The experiment shows that the supramolecular species $\mathrm{Mo}_{36} \mathrm{O}_{112}{ }^{8-}$ can be excluded as intermediate under hydrothermal conditions $\left(\mathrm{T}>100^{\circ} \mathrm{C}\right)$.

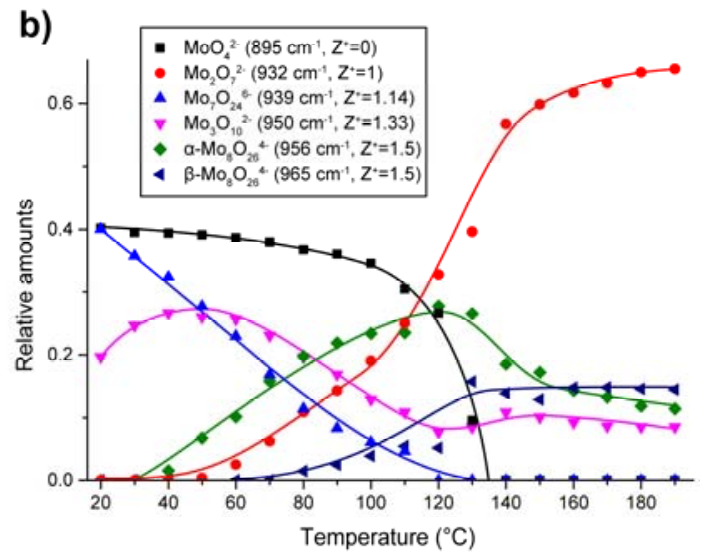

Figure 3. In situ Raman spectra recorded during heating of a $0.2 \mathrm{M}$ ammonium heptamolybdate solution from 20 to $190^{\circ} \mathrm{C}$ with the corresponding $\mathrm{pH}$ values (a) and species distribution plot derived from spectral deconvolution of the Raman spectra (b). The Z-value remains constant at 1.14 during the entire experiment (see Table S2, Supporting information).

depolymerisation and release of the required protons. Following this argument and considering the spectral shift of the $\mathrm{Mo}=\mathrm{O}$ vibration towards lower wavenumbers, this newly formed species with a peak maximum at $932 \mathrm{~cm}^{-1}$ requires a degree of polymerisation between ortho- and heptamolybdate. Dimolybdates, which are constituted either by corner-sharing tetraedra in a dimeric or by corner- and edge-molybdate units in the polymeric form, are found in literature with a $\mathrm{Mo}=\mathrm{O}$ band in the spectral range from 925 to $939 \mathrm{~cm}^{-1},{ }^{[19]}$ are the only stable molybdates to be expected with a $\mathrm{Z}^{+}$-value lower than heptamolybdate. At $\mathrm{T}>100^{\circ} \mathrm{C}$, a shoulder to the band at $932 \mathrm{~cm}^{-1}$ becomes visible resulting in a pronounced tail towards lower energy $\left(\sim 925 \mathrm{~cm}^{-1}\right)$ at $190^{\circ} \mathrm{C}$. In addition, a new broad band is observed at $889 \mathrm{~cm}^{-1}$. These trends may be interpreted in terms of ongoing restructuring and the formation of more open, chain-like structures, like in $\left[\mathrm{Mo}_{3} \mathrm{O}_{10}\right]^{2-},{ }^{[13 \mathrm{a}]}$ or $\left[\mathrm{Mo}_{4} \mathrm{O}_{13}\right]^{2-} \cdot{ }^{20]}$
Those findings now help with the interpretation of the spectra obtained from the experiment of Figure $2 \mathrm{~b}$ done at different $\mathrm{pH}$ at a temperature of $175^{\circ} \mathrm{C}$. In the neutral regime, the orthomolybdate is the dominant species, characterized by the band at $890 \mathrm{~cm}^{-1}$. On addition of $\mathrm{HNO}_{3}$, this band decreases and the band at $932 \mathrm{~cm}^{-1}$ with a shoulder clearly visible at $925 \mathrm{~cm}^{-1}$, which are missing at $25^{\circ} \mathrm{C}$, increase in intensity. The band at $925 \mathrm{~cm}^{-1}$, which persists until $\mathrm{pH}=2.5$, may indicate the presence of chain-like, oligomeric structures like in trimolybdates. ${ }^{[13 a, 22]}$ As discussed in the heating experiment of heptamolybdate, the band at $932 \mathrm{~cm}^{-1}$ can be attributed to dimolybdate species. This is the first example showing its presence in solution at $\mathrm{pH}=7$. While at low temperatures, $\alpha$-octamolybdate is formed at $\mathrm{pH} 3.0$ (band at $958 \mathrm{~cm}^{-1}$ ), at $175^{\circ} \mathrm{C}$ it is only observed as a broad shoulder around $955 \mathrm{~cm}^{-1}$ indicating an accelerated transformation into the $\beta$-modification of the octamolybdate $\left(965 \mathrm{~cm}^{-1}\right)$. The breaking of bonds and structural rearrangement in the transformation from the $\alpha$ - to the $\beta$ - 
modification of the octamolybdate has been discussed by Wang et al. to be enhanced by the formation of hydrogen bonds with ammonium in the solution. ${ }^{[23]}$ From this point of view, acidification of the solution and temperature increase

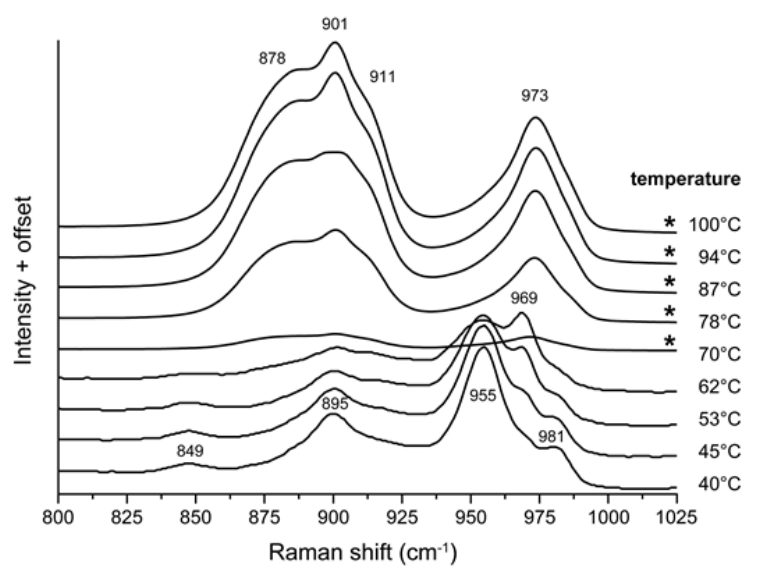

Figure 4. In Situ Raman spectra recorded during heating of a $\mathrm{Mo}_{36} \mathrm{O}_{112}{ }^{8-}$ solution (initial $\mathrm{pH}=1.5$ ) and formation of the hexagonal- $\mathrm{MoO}_{3}$ phase; due to the high scattering cross-section the spectra recorded at temperatures from $70-100^{\circ} \mathrm{C}$ marked by * have been scaled by a factor of 0.1 .

a)

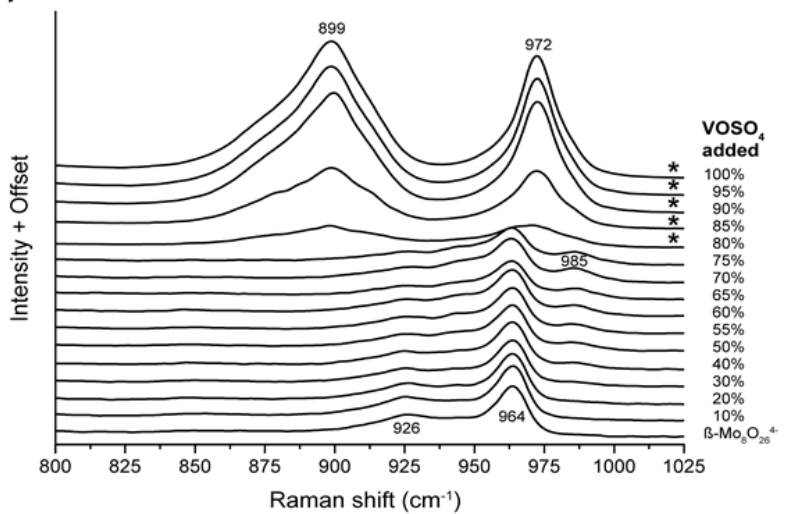

concentration typically applied in hydrothermal synthesis protocols of molybdenum-based mixed oxides. Our results clearly show that it is not useful to consider the fairly well known speciation at ambient conditions as a basis for discussion of phase formation under hydrothermal conditions. Furthermore, it becomes obvious that the $\mathrm{pH}$ value is an important controlling parameter also under hydrothermal conditions.

The impact of the $\mathrm{pH}$ on the formation of the ternary metal oxides is illustrated in the two comparative experiments shown in Figure 5. In the experiment presented in Figure 5a, vanadyl sulfate was pumped into the autoclave at $175^{\circ} \mathrm{C}$ to a molybdate solution that preferentially contains octamolybdate species. The $\mathrm{pH}$ has been adjusted by preceding addition of nitric acid until $\mathrm{pH}=2.1$. Raman spectroscopy confirms the predominance of $\beta-\mathrm{Mo}_{8} \mathrm{O}_{26}{ }^{4-}$ under these conditions. The addition of vanadyl ions under pressure at $175^{\circ} \mathrm{C}$ triggers the precipitation of hexagonal $\mathrm{MoO}_{3}$ in which molybdenum is partially substituted by vanadium. During addition of the vanadyl sulfate solution, the $\mathrm{pH}$ is found to drop from 2.1 to 1.0 which is the previously found $\mathrm{pH}$ range of the phase formation. The precipitation of hex.- $\mathrm{MoO}_{3}$ gets obvious by intense bands with maxima at 899 and $972 \mathrm{~cm}^{-1}$ and is also confirmed by XRD measurements (Figure S5, Supporting Information).

b)

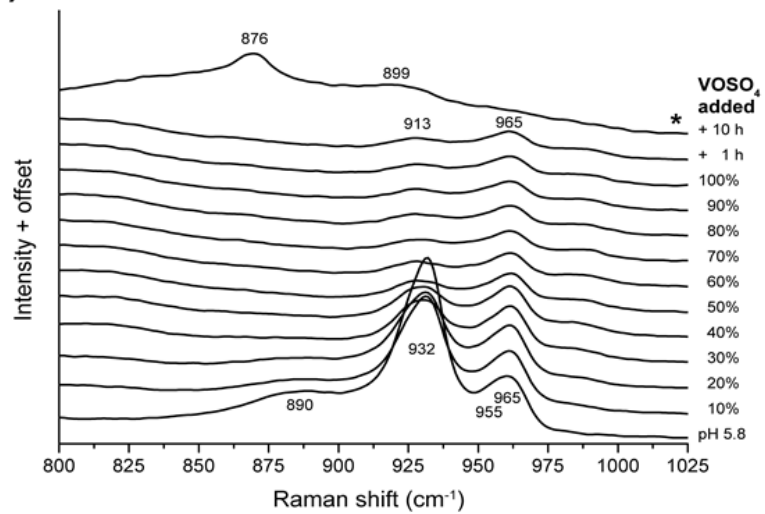

Figure 5. In situ Raman spectra recorded during the addition of a vanadyl sulfate solution at $0.5 \mathrm{ml} / \mathrm{min}$ to a solution of $\beta-\mathrm{Mo}_{8} \mathrm{O}_{26}{ }^{4-}$ at $\mathrm{pH} 2.1$ at $175^{\circ} \mathrm{C}$ (a) and a molybdate solution at $\mathrm{pH} 5.8$ at $200^{\circ} \mathrm{C}$ (b). Bands marked with * have been scaled for better comparison by the factors of 0.1 for (a) and 2 for (b).

should benefit the formation of $\beta-\mathrm{Mo}_{8} \mathrm{O}_{26}{ }^{4-}$ in agreement with our experimental results. The spectra between $\mathrm{pH} 3.0$ and 2.0 at $175^{\circ} \mathrm{C}$ mainly exhibit the bands of $\beta-\mathrm{Mo}_{8} \mathrm{O}_{26}{ }^{4-}$ Instead of bands due to $\mathrm{Mo}_{36} \mathrm{O}_{112}{ }^{8-}$, which has been shown to be instable at high temperatures (Figure 4), the characteristic bands of the hexagonal $\mathrm{MoO}_{3}$ phase are observed at $\mathrm{pH} 1.5$ and below, ${ }^{[24]}$ which precipitates from the solution as a fine yellowish powder. The formation of the phase was confirmed by XRD (Figure S4, Supporting Information). At normal pressure, the hexagonal $\mathrm{MoO}_{3}$ phase is precipitated at lower $\mathrm{pH}$ value $(\mathrm{pH}=1)$ and lower temperatures. ${ }^{[25]}$

In summary, the speciation of molybdates in $0.2 \mathrm{M}$ aqueous solution under hydrothermal conditions differs substantially from the speciation at room temperature at comparable $\mathrm{pH}$ values. This has been shown for the $\mathrm{pH}$ range between 7 and 1 at $175^{\circ} \mathrm{C}$ (Figure 2b) and for a solution of molybdates under autogenous $\mathrm{pH}$ and pressure between 170 and $190^{\circ} \mathrm{C}$ (Figure 3), temperatures and
The more open, chain-like structures of di- and trimolybdates that prevail in molybdate solution at a $\mathrm{pH}$ of 5.8 (see Figure 3) show differing reactivity. The higher temperature of $200^{\circ} \mathrm{C}$ was applied to maximise the occurrence of dimolybdate species in the solution (Figure $3 b)$. As it becomes apparent from Figure $5 \mathrm{~b}$, the reaction with vanadyl sulphate added at $200^{\circ} \mathrm{C}$ preferentially consumes these species. The intensities of the octamolybdate bands are hardly affected by vanadyl sulfate addition, which finally results in the formation of a nanocrystalline material mainly composed of the bronze-like "M1" structure at a final pH of 3.0 (ICSD 55097; Figure S6, Supporting Information) indicated by the peaks at 776 and $899 \mathrm{~cm}^{-1}$. 3$]$

\section{Conclusions}

The speciation of molybdates under hydrothermal conditions differs significantly from the speciation under 
ambient conditions at comparable $\mathrm{pH}$ values basically due to the thermal stability of the species involved in the equilibria in aqueous solution. At temperatures usually applied in hydrothermal syntheses $\left(170-200^{\circ} \mathrm{C}\right)$, less dense, chain-like structures are preferentially formed in the $\mathrm{pH}$ range between 6 and 5 (autogenous $\mathrm{pH}$ ). In acidic solutions $(\mathrm{pH}<2)$, supramolecular species, like $\mathrm{Mo}_{36} \mathrm{O}_{112}{ }^{8-}$ do not occur. Instead, octamolybdate is the final molecular precursor of precipitation reactions that was detectable by Raman spectroscopy. The different precursor species show differing reactivity with vanadyl sulfate resulting in the formation of mixed MoV oxides with either hexagonal or bronze-like structure.

The current work clearly demonstrates the power of in situ spectroscopy as a tool to improve our understanding of the inorganic reactions occurring under hydrothermal conditions Elucidation of nucleation and growth of solid particles requires first of all knowledge about the molecular and supra-molecular precursors occurring under the applied conditions in solution. The present work shows that the broad knowledge concerning the speciation of polyoxometalates in aqueous solution under ambient conditions cannot be transferred to the situation inside an autoclave at high temperatures. The synthesis of mixed $\mathrm{MoV}$ oxides starting from different molecular precursors illustrates that based on in situ spectroscopy, an interactive synthesis is possible that opens up new prospects in controlled fabrication of nano-structured materials.

\section{Experimental Section}

The experiments were done in MiliPore ${ }^{\circledR}$ water with the use of commercially available chemicals: ammonium heptamolybdate $\left(\mathrm{NH}_{4}\right)_{6} \mathrm{Mo}_{7} \mathrm{O}_{24} \cdot 4 \mathrm{H}_{2} \mathrm{O}$ (Merck), vanadyl sulfate $\left(\mathrm{VOSO}_{4} \cdot 4 \mathrm{H}_{2} \mathrm{O}\right.$ (Acros Organics)) ammonia (20\%, Fluka) and $\mathrm{HNO}_{3}(20 \%$, Merck).

The autoclave setup used for these experiments has been designed together with Premex reactor AG for allowing simultaneous analysis of the reaction by Raman spectroscopy, $\mathrm{pH}$ measurements and power intake of the stirrer at temperatures up to $210^{\circ} \mathrm{C}$. Two different reactor vessels with a total volume of $400 \mathrm{ml}$ have been used, fabricated in one case of corrosion resistant stainless steel (1.4435) and in the other case of Hastelloy C-22 (2.4602). The vessels are heated through an external thermostat using silicon oil with a heat-rate of approx. $3 \mathrm{~K} / \mathrm{min}$. The solution is stirred by an anchor type stirrer with a rotation speed of 50-600 rpm. Beside measurement of the temperature and pressure inside the vessel, the used reactor allows for the insertion of a Raman probe (RAMANRXN1, immersion optic 1/4"OD (HC-276); Kaiser Optical Systems) and $\mathrm{pH}$ probes $\left(\mathrm{ZrO}_{2}\right.$ probe Model $\mathrm{A} 2$ and $\mathrm{Ag} / \mathrm{AgCl}$ reference electrode, both with a 1/2" outer tubing made from C-276; Corr Instruments), and is equipped with valves to add reactants into the vessel at any given time by use of an HPLC pump (Smartline pump 1050; Knauer). The Raman spectra were automatically recorded each $60 \mathrm{~s}$ at a wavelength of $785 \mathrm{~nm}$ with an exposure time of $30 \mathrm{~s}$, while the nitric acid was pumped inside the reactor at $0.25 \mathrm{ml} / \mathrm{min}$. The $\mathrm{pH}$ probes were calibrated by use of four buffer solutions at the given reaction temperatures prior to the experiments.

The deconvolution of the Raman spectra has been performed with the program Fityk ${ }^{[26]}$ allowing for the species with similar Z-values to be expected in the solution. The peak positions and relative intensities of the peaks were taken as in Table S1 (Supporting Information). Since the temperature shift is non-linear for all the bands of the sapphire probe, the shift of the $\mathrm{Mo}=\mathrm{O}$ vibrations has been allowed in the same range as for the band at $750 \mathrm{~cm}^{-1}$, which is the closest to the bands of interest.

For the $\mathrm{pH}$ dependent experiments, $9.18 \mathrm{~g}\left(\mathrm{NH}_{4}\right)_{6} \mathrm{Mo}_{7} \mathrm{O}_{24} \cdot 4 \mathrm{H}_{2} \mathrm{O}$ were dissolved in $200 \mathrm{ml} \mathrm{H}_{2} \mathrm{O}$, giving a clear $0.25 \mathrm{M}$ solution with a pH of 5.4. Approximately $9 \mathrm{ml}$ ammonia were added to adjust the $\mathrm{pH}$ to 9.0 at room temperature. The solution was then transferred to the autoclave reactor and the temperature set to 25 or $175^{\circ} \mathrm{C}$, respectively. After reaching the target temperature, the acid was slowly dosed reaching a final volume of $260 \mathrm{ml}$ (final concentration $0.2 \mathrm{M}$ )

In the heating experiment, $9.18 \mathrm{~g}$ heptamolybdate were dissolved in $260 \mathrm{ml}$ of water to give a $0.2 \mathrm{M}$ solution and slowly heated to $190^{\circ} \mathrm{C}$ at a heat-rate of $3 \mathrm{~K} / \mathrm{min}$.

The reactivity investigation of molybdates at different $\mathrm{pH}$ on the addition of $\mathrm{VOSO}_{4}$ has been carried out using a solution of $9.18 \mathrm{~g}$ $\left(\mathrm{NH}_{4}\right)_{6} \mathrm{Mo}_{7} \mathrm{O}_{24} \cdot 4 \mathrm{H}_{2} \mathrm{O}$ in $230 \mathrm{ml} \mathrm{H} \mathrm{H}_{2} \mathrm{O}$ at $\mathrm{pH} 2.1$ and 5.8 at temperatures of 175 and $200^{\circ} \mathrm{C}$, respectively and slowly pumping a solution of $3.3 \mathrm{~g} \mathrm{VOSO}_{4} \cdot 5 \mathrm{H}_{2} \mathrm{O}$ in $30 \mathrm{ml} \mathrm{H}_{2} \mathrm{O}$ at a pump rate of $0.5 \mathrm{ml} / \mathrm{min}$. The hydrothermal product obtained in the experiment shown in Figure $5 \mathrm{~b}$ has been washed with oxalic acid $(0.25 \mathrm{M})$ at $60^{\circ} \mathrm{C}$ for $30 \mathrm{~min}$ and thermally treated at $400^{\circ} \mathrm{C}$ in argon for $2 \mathrm{~h}$ afterwards.

\section{Acknowledgement}

Financial support by the BASF is gratefully acknowledged. The authors thank Dr. Frank Girgsdies, Jasmin Allan, Stephen Lohr, and Mateusz Jastak for scientific discussions and experimental support.

\section{References}

a) C. S. Cundy, P. A. Cox, Microporous and Mesoporous Materials 2005, 82, 1-78; b) B. L. Cushing, V. L.

Kolesnichenko, C. J. O'Connor, Chemical Reviews 2004, 104, 3893-3946; c) G. R. Patzke, Y. Zhou, R. Kontic, F. Conrad, Angewandte Chemie International Edition 2011, 50, 826-859; d) A. Trunschke, in Chemical Energy Storage (Ed.: R. Schlögl), Walter de Gruyter GmbH, Berlin/Boston, 2013, pp. 277-301.

[2] F. Schüth, P. Bussian, P. Ågren, S. Schunk, M. Lindén, Solid State Sciences 2001, 3, 801-808.

[3] M. Sanchez Sanchez, F. Girgsdies, M. Jastak, P. Kube, R. Schlögl, A. Trunschke, Angewandte Chemie International Edition 2012, 51, 7194-7197.

[4] a) S. Borg, W. Liu, B. Etschmann, Y. Tian, J. Brugger, Geochimica et Cosmochimica Acta 2012, 92, 292-307; b) T. Kashiwabara, Y. Takahashi, M. Tanimizu, A. Usui, Geochimica et Cosmochimica Acta 2011, 75, 5762-5784. D. Pan, L. Spanu, B. Harrison, D. A. Sverjensky, G. Galli, Proceedings of the National Academy of Sciences 2013, 110, 6646-6650.

[6] a) D.-L. Long, R. Tsunashima, L. Cronin, Angewandte Chemie International Edition 2010, 49, 1736-1758; b) $\mathrm{H}$ N. Miras, J. Yan, D.-L. Long, L. Cronin, Chemical Society Reviews 2012, 41, 7403-7430; c) M. T. Pope, A. 
Müller, Angewandte Chemie International Edition in English 1991, 30, 34-48.

[7] A. V. Bandura, S. N. Lvov, Journal of Physical and Chemical Reference Data 2006, 35, 15-30.

[8] M. T. Pope, Heteropoly and Isopoly Oxometalates, Springer-Verlag, Berlin, Heidelberg, New York, Tokyo, 1983.

[9] a) K.-H. Tytko, O. Glemser, in Advances in Inorganic Chemistry and Radiochemistry, Vol. Volume 19 (Eds.: H. J. Emeléus, A. G. Sharpe), Academic Press, 1976, pp. 239-315; b) K. H. Tytko, G. Baethe, K. Mehmke, Zeitschrift fuer Anorganische und Allgemeine Chemie 1987, 555, 98-108.

[10] a) J. Aveston, E. W. Anacker, J. S. Johnson, Inorganic Chemistry 1964, 3, 735-746; b) W. G. Baldwin, G. Wiese, Ark. Kemi 1968, 31, 419; c) M. Haeringer, J. P. Schwing, Bull. Sos. Chim. France 1967, 2, 708-718; d) C. V. Krishnan, M. Garnett, B. Hsiao, B. Chu, International Journal of Electrochemical Science 2007, 2, 29-51; e) Y. Sasaki, I. Lindqvist, L. G. Sillén, Journal of Inorganic and Nuclear Chemistry 1959, 9, 93-94; f) K. H. Tytko, G. Baethe, E.-R. Hirschfeld, K. Mehmke, D. Stellhorn, Zeitschrift für anorganische und allgemeine Chemie 1983, 503, 43-66.

[11] T. Ozeki, H. Kihara, S. Ikeda, Analytical Chemistry 1988, 60, 2055-2059.

[12] a) D. K. Walanda, R. C. Burns, G. A. Lawrance, E. I. von Nagy-Felsobuki, Journal of the Chemical Society, Dalton Transactions 1999, 311-322; b) L. Vilà-Nadal, E. F. Wilson, H. N. Miras, A. Rodríguez-Fortea, L. Cronin, J. M. Poblet, Inorganic Chemistry 2011, 50, 7811-7819.

[13] a) S. Himeno, H. Niiya, T. Ueda, Bulletin of the Chemical Society of Japan 1997, 70, 631-637; b) K. Y. S. Ng, E. Gulari, Polyhedron 1984, 3, 1001-1011; c) T. Ozeki, H. Kihara, S. Hikime, Analytical Chemistry 1987, 59, 945-950; d) K.-H. Tytko, B. Schönfeld, B. Buss, O. Glemser, Angewandte Chemie 1973, 85, 305-307; e) K. H. Tytko, G. Petridis, B. Schoenfeld, Zeitschrift fuer Naturforschung, Teil B: Anorganische Chemie, Organische Chemie 1980, 35b, 45-56; f) K. H. Tytko, B. Schonfeld, Zeitschrift Fur Naturforschung Section B-a Journal of Chemical Sciences 1975, 30, 471-484; g) W. P. Griffith, P. J. B. Lesniak, Journal of the Chemical Society A: Inorganic, Physical, Theoretical 1969, 10661071.

[14] K. Murata, S. Ikeda, Spectrochimica Acta Part A: Molecular Spectroscopy 1983, 39, 787-794.

[15] a) V. W. Day, M. F. Fredrich, W. G. Klemperer, W. Shum, Journal of the American Chemical Society 1977, 99, 952-953; b) A. J. Bridgeman, The Journal of Physical Chemistry A 2002, 106, 12151-12160.

[16] L. Kihlborg, Arkiv Kemi 1963, 21, 427.

[17] P. DeSanto, Jr., D. J. Buttrey, R. K. Grasselli, C. G. Lugmair, A. F. Volpe, Jr., B. H. Toby, T. Vogt, Zeitschrift fuer Kristallographie 2004, 219, 152-165.

[18] O. F. Oyerinde, C. L. Weeks, A. D. Anbar, T. G. Spiro, Inorganica Chimica Acta 2008, 361, 1000-1007.

[19] a) V. V. Fomichev, M. E. Poloznikova, O. I. Kondratov, Russian Chemical Reviewa 1992, 61, 877-888 ; b) G. D. Saraiva, W. Paraguassu, M. Maczka, P. T. C. Freire, F. F. de Sousa, J. Mendes Filho, Journal of Raman Spectroscopy 2011, 42, 1114-1119.

[20] A. Briceño, R. Atencio, Acta Crystallographica Section E 2004, 60, i47-i49.

[21] J. Guo, P. Zavalij, M. S. Whittingham, Journal of Solid State Chemistry 1995, 117, 323-332.

[22] M. Oszajca, N. Juszczyk, W. Łasocha, Journal of Molecular Structure 2010, 965, 131-136.

[23] X.-J. Wang, B.-S. Kang, C.-Y. Su, K.-B. Yu, H.-X. Zhang, Z.-N. Chen, Polyhedron 1999, 18, 3371-3375.

[24] a) V. Atuchin, T. Gavrilova, V. Kostrovsky, L. Pokrovsky, I. Troitskaia, Inorganic Materials 2008, 44, 622-627; b) L. Seguin, M. Figlarz, R. Cavagnat, J. C. Lassègues, Spectrochimica Acta Part A: Molecular and Biomolecular Spectroscopy 1995, 51, 1323-1344.

[25] O. Mougin, J.-L. Dubois, F. Mathieu, A. Rousset, Journal of Solid State Chemistry 2000, 152, 353-360.

[26] M. Wojdyr, Journal of Applied Crystallography 2010, 43, 1126-1128

Received: ((will be filled in by the editorial staff)) Published online: ((will be filled in by the editorial staff)) 


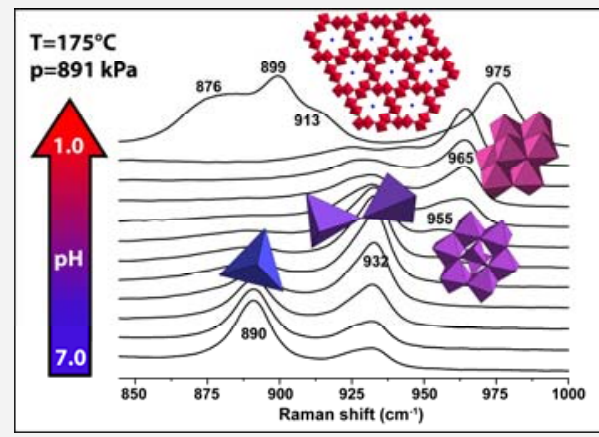

J. Noack, F. Rosowski, R. Schlögl, A. Trunschke* Page No.

Speciation of Molybdates under Hydrothermal Conditions 